\title{
PLANTINGA ON PROVIDENCE AND PHYSICS
}

\author{
HANS HALVORSON
}

Princeton University

In Where the Conflict Really Lies, Alvin Plantinga argues that there is nothing more than a superficial conflict between contemporary science and traditional Theistic belief. He goes on to argue that there is a deep conflict between contemporary science and atheistic naturalism. I will concern myself here with only one part of Plantinga's argument for the first thesis, i.e. that there is only superficial conflict between science and Christian Theism. I will focus, in particular, on the argument from Chapters 3 and 4 to the effect that there is no conflict at all - not even superficial conflict - between contemporary physics and the claim that God can, and does, on occasion interact in 'special' ways with God's creation.

In the spirit of constructive criticism, I will raise four issues about Plantinga's discussion of providence and physics. Each of these issues can be resolved, I would suggest, via a more thoroughgoing application of Plantinga's 'Reformed' epistemological outlook. First, Plantinga indicates that if God acts in history, then the laws of physics are not deterministic. But from the point of view of Reformed epistemology, the character of the laws of physics should be irrelevant to one's warrant in believing that God has acted. Second, Plantinga argues that divine intervention is consistent with the laws of Newtonian mechanics, since these laws carry provisos. However, the provisos leave room only for intervention by other physical systems. Third, Plantinga proposes that God could cause events by exploiting 'collapse' of the quantum wavefunction. However, this proposal only adds the sound of scientific respectability to theology; it doesn't actually use the science in any substantive way to correct or enrich theology. Finally, Plantinga's discussion presupposes that science aims to establish laws of nature, and that divinely caused events contravene the laws of nature (for closed systems). But 'Reformed' considerations suggest eliminating any dichotomy between 'law' and 'miracle'. 


\section{BELIEVING THAT GOD HAS ACTED}

Christian Theists certainly believe that nothing happens without God's permission - and so, in one sense, God is behind everything that happens. But Christian Theists have nuanced principles about when it is and is not appropriate to ascribe events to God. Here is one example (in the spirit of experimental philosophy): I asked an intellectually sophisticated Christian, but not a professional academic, two questions: First, is God responsible for the Newtown school shootings? Second, is God responsible for some particular events in your life? Unsurprisingly, the answers were No, and Yes. I suspect that this example is somewhat representative of the attitude of Christian Theists living in contemporary, scientific societies: they may not agree on the particular answers they give, but they all discriminate between events which God brought about, and events which God did not bring about. In any case, Christian Theism includes the claim that God is an agent who brings about particular events.

As Plantinga points out, however, several prominent theologians (e.g. Rudolf Bultmann, Langdon Gilkey) want to bring an end to this sort of talk. These theologians claim that describing God as active in the world is inconsistent with a 'scientific' worldview.

One of Plantinga's main objectives is to neutralize the claims of Bultmann and friends. But Plantinga does not defend the consistency of Newtonian (or quantum) physics and particular instances of divine action - or as philosophers might say, of token instances of divine action. That is, he does not argue that Newtonian physics would allow for the Red Sea to be parted, ${ }^{1}$ nor that Newtonian physics allows for people to rise from the dead, nor that quantum physics provided the mechanism for God to providentially steer Plantinga toward a career in philosophy. Rather, Plantinga defends the general claim that divine intervention type events are consistent with Newtonian and quantum physics. That is, he argues that events like the parting of the Red Sea, or the Resurrection of Jesus, or the multiplying of the Loaves and Fishes, are consistent with the laws of nature postulated by these theories.

${ }^{1}$ Oceanographers Naum Voltzinger and Alexei Androsov have recently explained using the differential equations of hydrodynamics - how the Red Sea might have parted. See Voltzinger, N. E. and A. A. Androsov, 'Modeling the Hydrodynamic Situation of the Exodus', Shirshov Institute of Oceanology (St. Petersburg Branch), Russian Academy of Sciences (2002). It's interesting to consider what presuppositions might motivate this sort of 'scientific' work, and how Voltzinger and Androsov's aims differ from Plantinga's. 
How does one go about defending a general possibility claim? On the one hand, one could show that specific instances are actual, and then the general possibility claim would follow. On the other hand, one could characterize the specific instances in terms of their shared properties - i.e. identify the type of events involved - and then give some sort of conceptual argument that these properties are not mutually exclusive. It is this second approach that Plantinga pursues. He defines a notion of 'divine intervention events', and he then argues that these sorts of events are allowed by the laws of physics (Newtonian physics, or quantum physics).

The problem with this latter strategy is that Plantinga has left himself open to two sorts of objections: first, one could object to Plantinga's argument that divine intervention events - as Plantinga has characterized them - are consistent with the laws of physics. Second, one could object to Plantinga's characterization of divine intervention events. The latter sort of objection might be made by somebody who actually agrees with Plantinga that God has acted in history, e.g. this objector might agree with Plantinga that Jesus rose from the dead.

Plantinga characterizes divine intervention type events in Section III of Chapter 4: an event $E$ results from intervention if $E$ s occurrence does not follow by nomological necessity from the previous state of the universe. Plantinga's definition of intervention has the following corollary: during any interval of time in which a system obeys a deterministic physical law, God does not intervene in that system. That claim might sound plausible enough, but it stands in some tension with traditional Christian ways of speaking about God's action. For example, a claim such as 'Jesus turned the water into wine', might count as a case of divine intervention (depending on whether water-to-wine transitions can occur in Newtonian physics), whereas 'God provided the harvest' would most likely not count as a case of divine intervention. My intuition, however, is that to classify the latter sort of case as not involving divine intervention would undercut the proper attitude towards such events. I suspect that the proper attitude of gratitude is to think that God was causally responsible for what was provided. But if we insist that the provision of the harvest didn't involve divine intervention, then wouldn't we be speaking with a forked tongue to thank God for it? Or should we include our thanks for the harvest among our more general thanks for the created order, and must we also thank God then just as much for the years of drought? 
Plantinga's focus on intervention - as opposed to, say, divine providence - might be seen as situating him somewhere in the 'right wing' of a continuum of views about how to think of God's agency in the world. In the extreme right wing, the 'scientific theologian' hopes to combine the best scientific theories and theology into one 'superscience' that describes all existing things and their causal relations. In this super-science, God would be one among the causal variables, and such a science would then clearly single out the God-caused events. On the other hand, in the extreme left wing, the 'mystical theologian' claims that events can have a religious interpretation or significance that transcends the purely scientific description of those events. For example, the mystical theologian might say that one and the same event $E$ has both a description as an ordinary physical event (caused by other physical events), and also a description as an event with deep religious significance.

But the right-wing view of divine action sits uneasily with Plantinga's views on religious epistemology. Unlike Plantinga, a natural theologian is committed to the idea that theological facts can receive evidential support from purely natural, or physical facts. So, for example, a natural theologian might claim that 'God is benevolent' receives evidential support from a purely physical description of the configuration of the universe. But given Plantinga's epistemological position, the claim that 'God is benevolent' has warrant independent from our knowledge of the physical world. In a similar vein, couldn't Plantinga claim that ' $E$ is providential' is warranted even if that warrant does not derive from $E$ 's role in the best physical theory?

\section{NEWTONIAN LAWS AND PROVISOS}

Plantinga argues in Chapter 3 that the 'old picture' is consistent with divine action. Here the 'old picture' means Newtonian mechanics - or at least we can take that as the paradigm case. The picture here is of a world consisting of matter in motion, more particularly, of discrete objects whose positions and velocities are governed by deterministic laws of motion.

How does this Newtonian picture bear on the rationality of talking about God as interacting with the world? As Plantinga reminds us, several theologians (e.g. Bultmann) claim that the Newtonian picture precludes the theological doctrine. Well, of course, a 'picture' cannot 
literally be inconsistent with a proposition, theological or otherwise. So, if the theological doctrine is in conflict with the science, then the science must teach us some propositions that entail the negation of the theological proposition. And what are these Newtonian propositions supposed to be?

Plantinga claims that Newtonian science itself has no such proposition to offer, i.e. no proposition that conflicts with divine intervention. He then goes on to isolate a single addendum which, when combined with the deliverances of Newtonian physics, would be sufficient to rule out intervention: the universe is a closed system. Plantinga dubs the conjunction of Newtonian physics and causal closure the 'Laplacian picture'.

Plantinga claims that the causal closure claim is a 'metaphysical ancilla' on Newtonian physics. What does he mean by this claim, and how is it supposed to bear on our attitude towards the Laplacian picture? By saying that closure is a 'metaphysical ancilla', Plantinga might mean that it doesn't boost the predictive power of Newtonian physics, i.e. 'Newton + Causal Closure' makes the same predictions as 'Newton'. In other words, the closure principle is empirically vacuous. Two questions then arise: first, is that claim true, i.e. is causal closure empirically vacuous? Plantinga could consistently deny its empirical bite (since his epistemology of religion doesn't require 'scientific' evidence of God's agency), but certain natural theologians (perhaps, e.g., Richard Swinburne) would be forced to say that causal closure has empirical import, and that it has been falsified. Second, even if 'Newton + Causal Closure' is empirically equivalent to just 'Newton', might not the former have some additional theoretical virtues that make it preferable as a scientific theory?

But let's grant Plantinga that Newtonian physics doesn't need the closure claim. Without the closure claim, Plantinga argues, Newtonian physics is consistent with divine intervention. As we saw earlier, Plantinga claims that divine intervention requires physical indeterminism. But aren't the laws of Newtonian physics deterministic?

In order to understand Plantinga's claim that the Newtonian laws are not deterministic, let's consider an example: suppose that $E$ is brought about by divine intervention, in particular, that the previous state of the universe and the laws of nature together did not entail that $E$ would occur. For example, $E$ might consist of an increase of the total energy of the 
universe. Plantinga correctly points out that $E$ itself would not violate the law of conservation of energy, for a correct formulation of that law reads:

$C E$ : When a system is causally closed, then its total energy is conserved. Using $L=$ 'energy is conserved', the law of conservation of energy has the form:

$C E$ : When a system is causally closed, then $L$.

Plantinga claims, in fact, that all the laws of Newtonian physics should be cast in this conditional form, i.e. their correct formulation includes the prefix, 'When a system is causally closed .... If Plantinga's claim can be sustained, then Newtonian physics is consistent with divine intervention.

There is a lively debate in the philosophy of science literature about whether the laws of nature include implicit provisos about their range of application (see Lange 1993; Earman and Roberts 1999). So, Plantinga is certainly in good company in his view of the laws of nature. Nonetheless, it's not clear that these provisos would be of the right sort to support Plantinga's position. Consider again the case of $C E$ : the energy of a closed system is conserved. Imagine a physicist who wants to test $C E$ : he measures the energy of his system at some time $t$, and then returns later at $t^{\prime}$ to take another energy measurement. If the total energy is different at $t$ ' than it was at $t$, then the experimenter has two options: either he can conclude that his system was not actually closed, or he can conclude that $C E$ is violated. In order to render $C E$ non-vacuous, the experimenter then needs a way to rule out the former hypothesis, i.e. that his system was open to external influence between $t$ and $t^{\prime}$. Of course, ruling out external influence is a skill that experimenters have developed over time and with much practice; it is only because experimenters have an independent sense of when a system is isolated that $C E$ can be put to empirical test.

Conversely, $C E$ is not predictively vacuous because if a system $S$ violates $C E$, then $C E$ predicts that $S$ is included in a larger (physical) system $S$ ' that satisfies $C E$. Now, Plantinga might assent to my analysis, and go on to say that a violation of $C E$ could be taken as providing evidence that the universe $U$ is part of a larger system $U^{\prime}$ that satisfies $C E$ - in particular, $U^{\prime}$ would consist of the universe plus God. But if one starts talking about God as part of a composite system that satisfies conservation of energy, then I drop out of the discussion: I don't think that 'has energy $e$ ' is a predicate that we should apply to God. 
In other words, while I agree with Plantinga's hedging of the Newtonian laws, I don't like the idea that these laws are hedged because the universe is an 'open system' in the sense that local physical systems can be 'open'. Typically by 'open system' we mean a subsystem of a larger physical system. But since God is not physical, ${ }^{2}$ the universe is not a subsystem of some larger physical system.

So, on the positive side, in what sense should we think of the Newtonian laws as hedged? What are the limitations of these laws? One suggestion is that the language of physics is descriptively incomplete. In a naive sense, the language of physics would be descriptively complete if every property and every event type could be accurately represented using the language of physics (or using the representational apparatus of physics). Suppose, however, that the practice of physics is based on using a language that buys, say, clarity and efficiency at the cost of representational power. For example, some philosophers (such as Quine) say that the language of physics makes no use of modalities. Supposing that Quine is right about modalities in physics, one could follow Quine in asserting the descriptive adequacy of physics, and so reject modalities; alternatively, one could embrace modalities at the cost of rejecting the descriptive adequacy of physics.

In a different vein, let me also supply some further ammunition that Plantinga could use in his argument that Newtonian physics is consistent with divine intervention. Recall that for Plantinga, the consistency claim can be maintained so long as Newtonian physics is not universally deterministic. But there are simple models of Newtonian physics where determinism breaks down (see Norton 2003; Norton 2008). Moreover, some of the models of classical physics are intrinsically open to external intervention, i.e. nothing but ad hoc postulation can rule out the possibility of unaccounted for external influences on a system. For example, Earman (1986) points out that several classical spacetime theories allow for 'space invaders', i.e. objects which appear suddenly in spacetime without antecedent physical cause. (See (Earman 2008) for further examples where determinism fails in classical physics.)

Now, I would strongly suggest against looking for divine intervention at precisely these points where determinism breaks down in classical physics. (In Norton's example, determinism breaks down for a mass

${ }^{2}$ Westminster Shorter Catechism, Question 9: 'Q. Who is God? A. God is a Spirit, and does not have a body like men (Jn 4:24; 2 Cor 3:17; 1 Tim 1:17).' 
situated at the apex of a dome. Should we conclude then that divine intervention occurs at the apices of domes?) The take-home point of these examples, rather, is that scientific theories don't bear their metaphysical implications on their sleeves.

\section{AGAINST MICRO-THEOLOGY}

Plantinga has argued that even the old picture - deterministic, classical physics - presents little problem for the believer in divine action. How much less, then, should the new picture - indeterministic, quantum physics - cause worry for the Christian Theist. Indeed, Plantinga claims not only that quantum physics is consistent with divine action, but he suggests that quantum physics might describe the mechanism by which God works out his purposes. In this latter claim, Plantinga gives a (perhaps lukewarm) endorsement to the work of members of the 'Divine Action Project', who have attempted to develop a theory of divine action that is consistent with quantum physics. (We can understand why Plantinga might not be fully enthusiastic about the Divine Action Project. Given his argument in Ch. 3, we don't need new physics to tell us that special providence is possible. So Plantinga does not share the sense of urgency we see in the Divine Action Project.)

Plantinga's discussion displays his awareness of the fact that the physics (and philosophy) community is nowhere near consensus on the metaphysical (or epistemological) lessons of quantum physics. Some interpreters of quantum physics claim that the lesson is that the world is made of information rather than of particles or fields; some interpreters of quantum physics claim that the lesson is that the future is open (indeterminism). Suffice it to say, there remains quite a bit of freedom in interpreting quantum physics.

At the end of Ch. 4, Plantinga suggests that the Ghirardi, Rimini, Weber 'objective collapse' interpretation of quantum mechanics could be combined with a robust view of God's agency in the physical world. The important feature of GRW for this claim is that it postulates a stochastic dynamical law: the state of the world at a time, plus the laws of nature, do not determine the state of the world at all future times; there are some non-trivial probabilities for different outcomes. So, GRW theory is particularly congenial to a Theist who is an incompatibilist about physical determinism and divine action. 
I'm happy enough to see Plantinga settling on the GRW interpretation of quantum mechanics - undoubtedly a better physical theory than the original 'measurement collapse' account. Moreover, the GRW account seems to have the least amount of metaphysical baggage of any of the leading interpretations of quantum mechanics. However, I would caution Plantinga, and others, against becoming too attached to GRW as the story about 'how God does it'. Let me explain my reservations.

My primary reservation arises from restricting God's intentional activity to an over-specific location in the causal nexus - and a location not supported by revealed theology. If we took 'divine collapse causation' (DCC) too seriously, then we would end up saying that whenever God acted providentially in history, God did so indirectly by means of moving around some micro-objects. Perhaps that account is true - I don't have any great reason to rule it out - but it would certainly violate my sense of what Christians mean when they say things like 'God providentially brought it about that the child said, "tolle, lege"' I'm not sure that we gain anything by reinterpreting Augustine's claim as saying that God caused a certain wavefunction collapse which eventually led to the child uttering those famous words. In fact, I'm sure that we would lose something if we were to get distracted by the 'scientific account' of such providential events, instead of focusing on their intended meaning, i.e. their takehome point for us.

As Plantinga himself says, 'the warrant for belief in special divine action doesn't come from quantum mechanics or current science or indeed any science at all; these beliefs have their own independent source of warrant' (Plantinga 2011: 120). It is claims like this that exemplify the difference between Plantinga and members of the Divine Action Project. Of course, Plantinga thinks that physics gets a lot of things right; and Plantinga thinks that God acts. Therefore Plantinga thinks that there is some true story about how God's action meshes with the deliverances of physics. But working out such a story is going to be hard work, and it's not mandatory to postpone belief until the story has been completed. So, if someone pushes me on the consistency of my beliefs in God's agency with my commitment to current physics, I will probably side with Plantinga and say that God could act through divine collapse causation. But what would be the point of saying such a thing? Ideally, relating theology to science would help theology to say true things and to avoid saying false things. But the DCC story does not make any interesting predictions about which divine interventions did or did not occur. Thus, 
while DCC provides an interesting 'just so' story, attaching it to theology wouldn't make our theology any more scientific.

\section{LAWS OF NATURE: THEOLOGICAL AND PHILOSOPHICAL OBJECTIONS}

Why would some people have thought that divine agency is inconsistent with the methods and deliverances of contemporary science? I suggest that the problem is due largely to adopting an inadequate philosophy of science. There are many things to say on this score, but I'll focus just on the concept of a 'law of nature' - which has severe problems, both theological and philosophical.

First, while Christian Theists are committed to a concept of divine action, it's not clear that they need to think of divine action in contrast to 'laws of nature', or as contravening or transcending the (Aristotelian) 'natures' of things. In particular, we need not equate God's creation with the establishment of laws of nature; nor need we think of God's sustaining activity in terms of upholding natural laws. Of course, this suggestion will be controversial: the most influential account of divine action comes from Aquinas, who presupposes a broadly Aristotelian framework. But there is another strand in the Christian tradition - a strand running through the thought of Augustine, and taken up again in the protestant Reformation. Consider, for example, Reijer Hooykaas' description of the attitude of Isaacs Beeckman and Newton:

It is evident that the biblical conception of Beeckman and Newton overbridges the gap between Law and Miracle, natural and supernatural, and considers them as essentially on the same level. This seems to be in the line of the Augustinian tradition. To Augustine, miracle, so far from representing a violation of nature, is simply the (humanly speaking) obscure and incomprehensible in nature. 'Nature', he says, 'is all order and all miracle, but the miracle is the order .... Calvin, too, puts forward this view of the world and of life so characteristic of the Bible. He makes no essential distinction between ordinary events, belonging to the order of nature (the rising and setting of the sun), extraordinary events (great drought), and miraculous events. The term 'supernatural' is not used ... He recognizes that God has instituted an order of nature and invested things with powers, but he rejects the idea that only 'special' events require divine intervention. God's providence works in the most 
insignificant things; the sparrow on the roof, the lily of the field are under His personal care. (Hooykaas 1959: 211)

(Clearly, Hooykaas is expressing left-wing sentiments - in the sense of Section 2 above - about divine action.) Similarly, Karl Barth cautions that, '... we cannot hypostatize the concept of law, as though in our dealings with it we really had to do with the ruling representative and vice-regent of God' (Barth 1961: III.3). In general, this strand of Christian thought has endorsed particular claims about God's actions in history (e.g. that God parted the Red Sea) without adopting a general stance on whether these events fall under the laws of nature.

Second, philosophical considerations militate against the idea that science aims to establish laws of nature. Not only is the very idea of 'laws of nature' riddled with philosophical problems (see van Fraassen 1989), it makes better sense of the practice of science to think of it as aiming to produce models in which the phenomena can be embedded (see Giere 1999). Moreover, at least in physics, a model is a mathematical structure; thus, physics aims to represent phenomena via mathematical structures. But with this more accurate picture of the objectives of physics, the question of consistency - of divine intervention and physics - takes on a new aspect. From this point of view, the question becomes whether an event $E$, purportedly divinely caused, can be given a mathematical description. And the answer is obvious: surely it could be done, but doing so wouldn't give us the first bit of information about that event's relation to God.

\section{BIBLIOGRAPHY}

Barth, K. 1961. Church Dogmatics (Edinburgh: T. \& T. Clark)

Earman, J. 1986. A Primer on Determinism (New York: Springer)

Earman, J. 2008. 'How Determinism Can Fail in Classical Physics and How Quantum Physics Can (Sometimes) Provide a Cure, Philosophy of Science, 75 (5): 817-829

Earman, J., and J. Roberts. 1999. 'Ceteris Paribus, There is No Problem of Provisos', Synthese, 118 (3): 439-478

Giere, R. N. 1999. Science Without Laws (Chicago: University of Chicago Press) Hooykaas, R. 1959. Natural Law and Divine Miracle: A Historical-Critical Study

of the Principle of Uniformity in Geology, Biology, and Theology (Leiden: Brill) Lange, M. 1993. 'Natural Laws and the Problem of Provisos', Erkenntnis, 38 (2): 233-248 
Norton, J. D. 2003. 'Causation as Folk Science', Philosophers' Imprint, 3 (4), available at: <http://quod.lib.umich.edu/p/phimp/3521354.0003.004/1> [accessed 25/09/2013]

Norton, J. D. 2008. 'The Dome: An Unexpectedly Simple Failure of Determinism', Philosophy of Science, 75 (5): 786-798

Plantinga, A. 2011. Where the Conflict Really Lies (New York: Oxford University Press)

Van Fraassen, B. C. 1989. Laws and Symmetry (Oxford: Oxford University Press) 